\title{
Alfabetização matemática em MT Análise dos dados do Simec/SisPacto
}

\author{
Ângela Rita Christofolo de Mello*
}

RESUMO: $\mathrm{O}$ artigo socializa dados parciais da pesquisa para analisar as avaliações de Matemática no Simec/SisPacto pelos professores alfabetizadores de Mato Grosso, no início e no final de 2014. Os dados inseridos nos sistemas, a partir de "agrupadores" definidos pelo Pacto Nacional pela Alfabetização na Idade Certa (Pnaic) se referem aos direitos de aprendizagem de Matemática e foram concedidos pela Coordenação Geral do Pnaic em Mato Grosso vinculada à Universidade Federal de Mato Grosso, Campus Universitário de Rondonópolis (UFMT/CUR), em abril de 2015.

Palavras-chave: Alfabetização Matemática. Avaliação interna. Sistemas de Avaliação em MT.

\section{MT Mathematical Literacy in Mato Groso (MT) Analysis of data from Simec / SisPacto}

\begin{abstract}
The article uses partial data from research in order to analyze the evaluation of Mathematics according to the Simec / SisPacto by the literacy teachers in Mato Grosso, and was completed at the beginning and end of 2014. The data inserted in the systems, from "groupers" defined by the National Pact for Literacy at the right age (PNAIC), refers to rights to learn Mathematics, and were granted by the General Coordination of PNAIC in Mato Grosso linked to the Federal University of Mato Grosso, Campus Universitário de Rondonópolis (UFMT / CUR), in April 2015.
\end{abstract}

\footnotetext{
Licenciada em Pedagogia pela Universidade do Estado de Mato Grosso. Mestre em Educação pela Universidade Federal de Mato Grosso e Doutora em Educação pela Universidade Metodista de Piracicaba (BR). Professora da Universidade do Estado de Mato Grosso. Líder do Grupo de Estudo e Pesquisa de Formação Docente, Gestão e Prática Educacional (GEFOPE) da Universidade do Estado de Mato Grosso. Juara/ MT - Brasil. E-mail: <ritamello5@yahoo.com.br>.
} 
Keywords: Mathematical literacy. Internal evaluation. MT evaluation systems.

\section{Alfabetización matemática en el estado de Mato Grosso Análisis de los datos del Simec/SisPacto}

RESUMEN: El artículo presenta datos parciales de la investigación para analizar las evaluaciones de Matemáticas en el Simec/SisPacto por parte de los profesores alfabetizadores de Mato Grosso, al comienzo y al final de 2014. Los datos introducidos en los sistemas, a partir de "agrupadores" definidos por el Pacto Nacional pela Alfabetização na Idade Certa (Pnaic, Pacto Nacional por la Alfabetización en la Edad Adecuada), se refieren a los derechos de aprendizaje de Matemáticas y fueron facilitados por la Coordinación General del Pnaic en Mato Grosso vinculada a la Universidade Federal de Mato Grosso, Campus Universitario de Rondonópolis (UFMT/CUR), en abril de 2015.

Palabras clave: Alfabetización matemática. Evaluación interna. Sistemas de evaluación en Matemáticas

\section{Alphabétisation mathématique au Mato Grosso: Analyse des données Simec/SisPacto}

RÉSUMÉ: L'article rend public des données partielles des évaluations en Mathématiques du Simec/SisPacto des enseignants en alphabétisation du Mato Grosso, au début et à la fin de 2014. Les données insérées dans les systèmes, à partir de regroupements déterminés par le Pacte National pour l'Alphabétisation à l'âge adéquat ( Pnaic) se référent aux droits de l'apprentissage des Mathématiques et furent cédées par la Coordination Générale du Pnaic au Mato Grosso, attachée à l'Université Fédérale de Mato Grosso, Campus universitaire de Rondonópolis (UFMT/CUR), en avril 2015.

Mots-clés: Alphabétisation Mathématique. évaluation interne. Systèmes d'évaluations au Mato Grosso. 


\section{Introdução}

$\mathrm{P}$ esquisas realizadas pelo Instituto Nacional de Estudos e Pesquisas Educacionais Anísio Teixeira (Inep), nos últimos anos, informaram que, no Brasil, muitas crianças concluem o ciclo da alfabetização sem estarem alfabetizadas. Diante dos resultados, em 2013, o Ministério da Educação (MEC), assumiu um compromisso com os governos distrital, estaduais e municipais e instâncias não governamentais com o objetivo de alfabetizar todas as crianças brasileiras até aos oito anos de idade por meio da institucionalização do Pacto Nacional pela Alfabetização na Idade Certa (Pnaic) em todos os estados brasileiros, com proposição de ações para assegurar o direito à plena alfabetização de todas as crianças no ciclo da alfabetização (BRASIL, 2012).

O compromisso se articulou à realização de ações integradas, a exemplo da oferta de formação a todos os professores do ciclo da alfabetização. Vinculada às atividades de formação, incluíram-se as avaliações internas realizadas pelos professores alfabetizadores. Fundamentado em concepção progressista, o Pnaic considera a avaliação "uma ação intencional que se dá de modo multidirecional" (BRASIL, 2012, p. 5), ou seja, envolve várias pessoas e instâncias, pois "busca um sistema integrado de co-avaliação, no qual docentes, discentes e equipes de profissionais da escola e de outros sistemas avaliam e são avaliados" (Idem). Ao se referir às avaliações processuais, o Pnaic orienta que elas podem e devem ser realizadas continuadamente pelos professores. Neste sentido, disponibilizou um sistema informatizado (Simec/SisPacto) no qual os professores alfabetizadores inseriram, em 2014, no início e no final do ano letivo, dados resultantes das avaliações. O objetivo seria viabilizar o acompanhamento pelos professores e gestores e os ajustes necessários ao desenvolvimento da aprendizagem dos alfabetizandos.

Em Mato Grosso, a UFMT/CUR assumiu as ações do Pnaic. Trabalhamos com os dados disponibilizados nos sistemas para analisar o processo evolutivo de apropriação dos direitos de aprendizagem em Matemática das crianças matriculadas no ciclo da alfabetização em 2014.

O desenvolvimento da investigação pautou-se nestas indagações: os dados inseridos no Simec/SisPacto pelos professores, no início e no final do ano de 2014, imprimem um coerente processo evolutivo dos alfabetizandos em relação aos direitos de aprendizagem trabalhados? Há uma correlação neste processo evolutivo entre os direitos de aprendizagem definidos para a alfabetização Matemática? As avaliações analisadas informam os problemas deste processo e indicam quais os ajustes necessários para a superação destes? 


\section{Encaminhamentos metodológicos}

A pesquisa empírica, de abordagem qualitativa, sistematizou e analisou as avaliações das crianças matriculadas no ciclo da alfabetização em Mato Grosso, inseridas pelos professores no início e no final de 2014 no Simec/SisPacto. Optamos por esta abordagem por estarmos mergulhadas no campo da pesquisa (MARCONI e LAKATOS, 2002). Desse modo, os dados empíricos sistematizados e analisados (2014), articularam-se a um processo de coleta de demais informações interativas, possibilitadas pela nossa atuação enquanto professora formadora do Pnaic em Mato Grosso.

Os dados relativos aos direitos de aprendizagem de Matemática, distribuídos em agrupadores no Simec/SisPacto/UFMT/CUR, foram sistematizados e analisados. Para sistematizá-los, o primeiro exercício foi compilar os direitos gerais de aprendizagem e por ano de escolarização em quadros. A partir deste compilamento, passamos a tecer as análises, que seguem estruturadas nos itens subsequentes.

\section{Execução, controle e monitoramento}

O MEC possui um Sistema Integrado de Monitoramento Execução e Controle (Simec) disponível em um portal operacional e de gestão, que trata do orçamento e monitoramento das propostas on-line do governo federal na área da educação. O Sistema permite aos gestores verificar o andamento dos planos de ações articuladas (PAR) em suas cidades ${ }^{1}$. Já no Sistema de Monitoramento do Curso de Formação, voltado a orientador de estudo, vinculado ao Pacto Nacional pela Alfabetização na Idade Certa (SisPacto), o coordenador local, o orientador de estudo e os professores inserem dados sobre as ações do Pnaic por eles realizadas, em consonância com a função de cada um². Os registros sistematizados nos referidos sistemas informam que o quantitativo de alunos, de professores e de turmas cadastradas no início do ano foi maior do que o cadastrado no final deste mesmo ano, como demostra o Quadro 1:

\section{Quadro 1 - Número de alunos, de professores e de turmas de Alfabetização Matemática em Mato Grosso (início e fim/2014)}

\begin{tabular}{cc}
\hline Ensino Fundamental - 2014 (início) & Ensino Fundamental - 2014 (fim) \\
\hline № de Alunos: 127.939 & № de Alunos: 99.344 \\
№ de Professores: 5.556 & № de Professores: 4.331 \\
№ de Turmas: 6.420 & № de Turmas: 4.903 \\
\hline
\end{tabular}

Fonte: Simec.gov.mec.br/sispacto2/sispacto2.php?modulo=relatorio/relatoriospersonalizados\&acao=Acesso em abril de 2015. Adaptado pelas autoras. 
Estes números correspondem aos alunos matriculados nos três primeiros anos da escolarização básica, denominado pelo Pnaic de "Ciclo da Alfabetização". A diferença entre os números iniciais e finais é explicada pela desistência dos professores do curso de formação. Este aspecto foi antecipadamente anunciado pelo MEC, que, por meio do SisPacto, previu uma quebra de $20 \%$ no número de professores iniciantes (oriundo do Censo Escolar) como sugestão para certificação. Os principais fatores responsáveis por esta queda se devem às licenças médicas e licenças prêmios.

\section{Direitos de alfabetização matemática}

Apresentamos neste item os dados sistematizados da avaliação de 13 dos 17 agrupadores de Matemática inseridos no Simec/SisPacto no início e no final do ano de 2014. Os direitos de alfabetização estão relacionados à apropriação de conhecimentos que ajudam o ser humano a se encontrar no mundo, "a compreender a realidade natural e social na qual está inserido e a se colocar de forma ativa nas relações sociais" (TELES, 2014, p. 41). Assim, a apropriação de conhecimentos articula-se à superação das desigualdades sociais e ao pleno exercício da cidadania. Com esta compreensão, a formação continuada ofertada aos alfabetizadores pelo Pnaic em 2014, em consonância com o material elaborado para este fim, assumiu "a perspectiva da Educação Matemática que tem como eixo central a resolução de situações-problema e o desenvolvimento do pensamento lógico" (TELES, 2014, p. 41), bem como a defesa dos conhecimentos matemáticos como direitos de aprendizagem de todos.

O material elencou cinco eixos estruturantes: número e operações; pensamento algébrico; espaço e forma/geometria; grandezas e medidas; tratamento da informação/ estatística e probabilidade. Destes eixos desdobraram-se os 17 agrupadores que seguem, parcialmente analisados neste texto. Apesar de os eixos estruturantes "serem apresentados separadamente, para fins de organização, devem ser abordados de forma integrada para proporcionarem experiências com as práticas de representar, pois são constituídos por conceitos, propriedades, estruturas e relações" (TELES, 2014, p. 43).

Em relação à orientação progressiva do conhecimento pela criança, o material do Pnaic recomenda que estes direitos sejam trabalhados em espiral, ou seja, retomados e aprofundados continuadamente, no decorrer do ciclo e posteriormente. Contudo, há uma orientação dos momentos em que os conhecimentos devam ser introduzidos, aprofundados e consolidados. Embora reconheça que nem sempre é "possível delimitar um momento específico para que os conhecimentos e as capacidades estejam consolidados" (Idem). 


\section{Quadro 2 - Agrupador 2 (início e fim/2014)}

\begin{tabular}{l|c|c|c|c|c|c|c}
\hline $\begin{array}{l}\text { Associa a contagem } \\
\text { de objetos (mais que } \\
\text { 20), ordenados ou } \\
\text { não, à sua respectiva } \\
\text { representação. }\end{array}$ & Sim & $\%$ & Parc. & $\%$ & Não & $\%$ & Total \\
\hline Início & 87122 & 67,80 & 23167 & 18,00 & 18289 & 14,20 & 128578 \\
\hline Fim & 96777 & 86,20 & 10737 & 9,60 & 4734 & 4,20 & 112248 \\
\hline
\end{tabular}

Fonte: Idem Quadro 1.

O Quadro 2 mostra que 41.456 crianças associavam parcialmente ou não associavam a contagem de objetos (mais que 20), ordenados ou não, à sua respectiva representação no início de 2014. Após um ano de trabalho, o percentual de crianças que não tinha o referido direito consolidado baixou de $14,20 \%$ para 4,20\%. Segundo Lopes et al (2014) este conhecimento começa a ser construído fora dos bancos escolares e a interação da criança nos espaços históricos, sociais e culturais permite a ela vivenciar situações que podem promover o aprendizado. Desse modo, quando a criança inicia o seu processo de escolarização já possui "razoável e variado repertório de experiências sobre as características das 'coisas do mundo'"' (Idem, p. 43).

Como demostra o Quadro 2 muitas crianças podem não ter vivenciado estas práticas sociais ou se vivenciaram não compreenderam. Para que elas se apropriem deste conhecimento, a escola precisa trabalhar, por meio de diversas atividades, a regra que orienta a sequência dos números naturais, ou seja, o acréscimo de mais um. Dominar os princípios da contagem significa "compreender vários nexos conceituais, como correspondência um a um, agrupamento, representação etc., durante o processo de contar" (LOPES et al, 2014, p. 45). Ao construir esse direito, a criança compreenderá que, "independente das qualidades dos objetos que compõem a coleção [...], o processo de contagem ocorre segundo esses princípios" (Idem).

Mocrosky et al (2014) afirmam que o professor precisa avaliar quando o aluno apenas recita a sequência numérica por que a memorizou e quando ele conta com sentido numérico, mesmo porque o "último processo só ocorre com o desenvolvimento da estrutura lógico-matemática" (Idem, p. 66). Entretanto "não há uma idade definida para que se aprenda a contar, mas, ao perceber que o aluno não desenvolveu tal habilidade, é necessário retomar o trabalho com contagens de modo a subsidiar o processo de alfabetização matemática" (Idem). Neste caso, aproximadamente 15.471 crianças mato-grossenses aguardavam por esta retomada no final de 2014. 
Quadro 3 - Agrupador 3 (início e fim/2014)

\begin{tabular}{l|c|c|c|c|c|c|c}
\hline $\begin{array}{l}\text { Compara e ordena } \\
\text { números naturais. }\end{array}$ & Sim & $\%$ & Parc. & $\%$ & Não & $\%$ & Total \\
\hline Início & 87908 & 68,40 & 25242 & 19,60 & 15428 & 12,00 & 128578 \\
\hline Fim & 95855 & 85,40 & 11603 & 10,30 & 4777 & 4,30 & 112235 \\
\hline
\end{tabular}

Fonte: Idem Quadro 1.

Comparar e ordenar números naturais é mais uma prática social que a criança tem o direito de aprender para se tornar numeralizada. No início de 2014, as avaliações realizadas pelas alfabetizadoras indicaram que aproximadamente 40.670 crianças ainda não tinham construído este conhecimento. Os percentuais informam que em média 14,60\% deste total não se apropriaram deste direito no final desse ano. Entretanto, a construção do conhecimento impõe atividades de contagem diferenciadas e continuadas. Mesmo porque "a ordenação permite estabelecer uma organização entre os objetos, não necessariamente espacial, e facilita contar todos os elementos de uma coleção sem que algum seja ignorado ou contado mais de uma vez" (MOCROSKY et al, 2014, p. 66).

\section{Quadro 4 - Agrupador 4 (início e fim/2014)}

\begin{tabular}{l|c|c|c|c|c|c|c}
\hline $\begin{array}{l}\text { Compõe e decompõe } \\
\text { números com até } 3 \\
\text { algarismo. }\end{array}$ & Sim & $\%$ & Parc. & $\%$ & Não & $\%$ & Total \\
\hline Início & 53563 & 41,70 & 29229 & 22,70 & 45786 & 35,60 & 128578 \\
\hline Fim & 74302 & 66,20 & 21427 & 19,10 & 16519 & 14,70 & 112248 \\
\hline
\end{tabular}

Fonte: Idem Quadro 1.

Segundo Spinillo (2014) este conhecimento relaciona-se aos indicadores de "sentido numérico", sendo que "realizar cálculo mental e flexível" é um dos principais agrupadores deste sentido. Este, por sua vez, se caracteriza pelo "uso da composição e da decomposição das quantidades durante a resolução de situações-problema [...]" (p. 23). Os dados dispostos no Quadro 4 informam que aproximadamente 75.015 crianças tinham esse conhecimento parcialmente ou não construído no início de 2014. No final do ano, permaneceram com este conhecimento parcialmente ou não construído aproximadamente 37.946 crianças. O número pode estar relacionado à não-valorização de procedimentos alternativos pela escola, "por serem distintos dos procedimentos escolares típicos da matemática escrita e do uso de algorítmicos, esses procedimentos alternativos raramente são valorizados e explorados apropriadamente no contexto escolar" (SPINILO, 2014, p. 23). Todavia, a prática de compor e decompor números permite realizar aproximações, arredondamentos e pontos de referência, conhecimentos que podem "favorecer 
a compreensão acerca das relações matemáticas que estão subjacentes aos algoritmos e relacionadas às propriedades das operações" (Idem).

\section{Quadro 5 - Agrupador 6 (início e fim/2014)}

\begin{tabular}{l|c|c|c|c|c|c|c}
\hline $\begin{array}{l}\text { Resolve problemas que } \\
\text { demandam as ações de } \\
\text { comparar e completar } \\
\text { quantidades. }\end{array}$ & Sim & $\%$ & Parc. & $\%$ & Não & $\%$ & Total \\
\hline Início & 66807 & 52,00 & 34833 & 27,10 & 26938 & 21,00 & 128578 \\
\hline Fim & 85714 & 76,40 & 18565 & 15,50 & 7969 & 7,10 & 112248 \\
\hline
\end{tabular}

Fonte: Idem Quadro 1.

Resolver situações, "problemas que demandam as ações de comparar e completar quantidades", é um conhecimento que precisa ser trabalhado para que a criança se aproprie dos conceitos de adição e de subtração. Problemas que envolvem situações de composição com uma das partes desconhecidas são recomendados para que o conhecimento seja construído, como também, envolvendo situações com transformação desconhecida ou ainda com situações de transformação com estado inicial desconhecido e situações de comparação. Em relação à apropriação deste conhecimento, Guerios et al (2014) afirmam que:

Em primeiro lugar, é preciso que as crianças interpretem a situação-problema vivenciada, compreendam o enunciado do problema, seja oral ou escrito. Ao compreenderem, poderão estabelecer relações entre o que a situação propõe por meio do enunciado e os conhecimentos matemáticos a ela pertinentes.

Neste sentido, o número de crianças que não tinha esse conhecimento construído, no início do ano de 2014, pode estar relacionado à dificuldade de interpretação de textos. No final desse ano, os dados inseridos pelas alfabetizadoras informaram que 26.534 crianças construíram parcialmente ou não os referidos direitos.

\section{Quadro 6 - Agrupador 7 (início e fim/2014)}

\begin{tabular}{l|c|c|c|c|c|c|c}
\hline $\begin{array}{l}\text { Efetua adições e } \\
\text { subtrações com e } \\
\text { sem agrupamento e } \\
\text { desagrupamento. }\end{array}$ & Sim & $\mathbf{\%}$ & Parc. & $\%$ & Não & $\%$ & Total \\
\hline Início & 60672 & 47,20 & 35465 & 27,60 & 32441 & 25,20 & 128578 \\
\hline Fim & 81416 & 72,50 & 20881 & 18,60 & 9951 & 8,90 & 112248 \\
\hline
\end{tabular}

Fonte: Idem Quadro 1. 
Guerios et al (2014a) afirmam que "fazer contas" é uma expressão corriqueira na sala de aula. Os cadernos elaborados para subsidiar a formação ofertada pelo Pnaic orientam que o professor explore diversos caminhos para efetuar estas operações, e que as crianças se apropriem do SND para realizar tais operações com facilidade. Pautadas nas propriedades desse sistema, as crianças poderão efetuar operações de adição e de subtração ao mesmo tempo em que podem ampliar a compreensão acerca do SND e da utilização de algoritmos ${ }^{3}$. Primeiramente, a criança deverá, por meio da manipulação de material concreto (Ábaco, Quadro Valor Lugar (QVL), Material Dourado, palitos, tampinhas, etc), efetuar operações sem agrupamentos/desagrupamentos ou reservas. Os dados dispostos no Quadro 6 mostram que aproximadamente 67.906 crianças estavam com esse conhecimento parcialmente ou não construído no início do ano de 2014. No final do ano, 72,50\% das crianças construíram este direito.

\section{Quadro 7 - Agrupador 8 (início e fim/2014)}

\begin{tabular}{l|c|c|c|c|c|c|c}
\hline $\begin{array}{l}\text { Resolve problemas } \\
\text { que envolvem as } \\
\text { ideias da multiplicação } \\
\text { (proporcionalidade, } \\
\text { combinatória). }\end{array}$ & Sim & $\%$ & Parc. & $\%$ & Não & $\%$ & Total \\
\hline Início & 39516 & 30,70 & 31951 & 29,80 & 57111 & 44,40 & 128578 \\
\hline Fim & 68987 & 61,50 & 24983 & 22,30 & 18253 & 16,30 & 112223 \\
\hline
\end{tabular}

Fonte: Idem Quadro 1.

Além da recomendação de que as operações básicas de adição, subtração, multiplicação e divisão sejam trabalhadas pelos alfabetizadores por meio de planejamento interdisciplinares e articulados as situações da vida humana e social, o material do Pnaic de Matemática/2014 orienta que estes conceitos sejam trabalhados a partir da resolução de situações problemas, mesmo porque, "aprender sobre adição, subtração, multiplicação e divisão requer aprender muito mais do que procedimentos de cálculo [...] é neste sentido, que se estabelece [...] um diálogo com a Resolução de Problemas (GUERIOS et al, 2014a, p. 07).

Ao tratar de resoluções de problemas que envolvem as ideias da multiplicação (proporcionalidade, combinatória), os dados informam um significativo número de crianças com este conhecimento parcialmente ou não construído. De um universo de aproximadamente 128.578 crianças matriculadas no ciclo da alfabetização em Mato Grosso no início do ano de 2014, aproximadamente 89.062 crianças estavam com esse direito parcialmente ou não construído. Apesar do progresso de aproximadamente 50\% destas crianças, perto de 43.236 crianças permaneceram com este direito parcialmente ou não construído. Entretanto: 
[...] para o desenvolvimento do raciocínio aditivo e multiplicativo é importante propor aos alunos problemas variados, envolvendo as várias situações que compõem os campos conceituais. Com isso estaremos oferecendo situações desafiadoras às crianças e evitando que resolvam problemas a partir da repetição de estratégias já conhecidas (ROLKOUSKI, 2014, p. 78).

Contudo, notadamente o que predomina no interior das salas de aula de alfabetização é "fazer contas de menos e de mais" desarticuladas de situações problemas. A realidade confirma que são muitas as barreiras a serem vencidas no interior das salas de aulas para que os professores possam inovar e reinventar a sua atuação docente.

\section{Quadro 8 - Agrupador 9 (início e fim/2014)}

\begin{tabular}{l|c|c|c|c|c|c|c}
\hline $\begin{array}{l}\text { Resolve problemas que } \\
\text { envolvem as ideias da } \\
\text { divisão (participação e } \\
\text { repartição). }\end{array}$ & Sim & $\%$ & Parc. & $\%$ & Não & $\%$ & Total \\
\hline Início & 36270 & 28,20 & 32816 & 25,50 & 59492 & 46,30 & 128578 \\
\hline Fim & 67611 & 60,20 & 25995 & 23,20 & 18629 & 16,60 & 112235 \\
\hline
\end{tabular}

Fonte: Idem Quadro 1.

O quantitativo de crianças que resolvem parcialmente ou não resolvem situações problema envolvendo as ideias da divisão (participação e repartição) foi de 92.308 no início de 2014. No final do referido ano aproximadamente 44.624 permaneceram com este conhecimento parcialmente ou não construído. No entanto, a riqueza e a diversidade de conhecimentos numéricos que as crianças possuem ao ingressar no ciclo da alfabetização, quando adequadamente explorados pela escola, permite a elas resolver situações problema. Porém, os modos próprios das crianças lidarem com situações problema proporcionados por sua vivência ainda são timidamente explorados no interior das salas de aula de alfabetização de Mato Grosso. Desse modo,

$$
\begin{aligned}
& \text { muitas vezes a atividade matemática escolar é organizada apenas a partir de } \\
& \text { exercícios nos quais a meta é aprender a realizar cálculos (mentais e escritos) e a } \\
& \text { usar algoritmos, de modo a tornar a rotina na sala de aula marcada por intermi- } \\
& \text { náveis exercícios sem significado para os alunos (GUERIOS et al, 2014a, p. 07). }
\end{aligned}
$$

Estas afirmações legitimam a importância e a necessidade da oferta de formação continuada aos professores. Como disposto do Quadro 8, de 46,30\% alfabetizandos que não tinham se apropriado do direito em questão, no início do ano de 2014, no final deste mesmo ano, o percentual baixou para $16,60 \%$. 
Quadro 9 - Agrupador 10 (início e fim/2014)

\begin{tabular}{l|c|c|c|c|c|c|c|}
\hline $\begin{array}{l}\text { Identifica figuras } \\
\text { geométricas } \\
\text { planas (quadrado, } \\
\text { retângulo, triângulo, } \\
\text { circunferência). }\end{array}$ & Sim & $\%$ & Parc. & $\%$ & Não & $\%$ & Total \\
\hline Início & 88037 & 68,50 & 25258 & 19,60 & 15283 & 11,90 & 128578 \\
\hline Fim & 97397 & 86,80 & 10894 & 9,70 & 3957 & 3,50 & 112248 \\
\hline
\end{tabular}

Fonte: Idem Quadro 1.

OCaderno de Geometria do Pnaic (BRASIL, 2014c), no texto "Iniciando a Conversa", destaca dois grandes objetivos alfabetizadores, quais sejam: possibilitar às crianças "construir noções de localização e movimentação no espaço físico para a orientação espacial em diferentes situações do cotidiano e reconhecer figuras geométricas presentes no ambiente" (p. 5). O direito de aprendizagem do Quadro 9 corresponde ao segundo objetivo. Os dados sistematizados indicam que aproximadamente 40.541 crianças mato-grossenses tinham este direito parcialmente ou não construído no início de 2014. No final do ano, em média, 13\% das crianças não se apropriaram deste direito.

A alfabetização geométrica ajuda as pessoas, dentre outras coisas, a ler o espaço que a circunda. Para tanto, ela precisa devolver nas crianças diferentes processos cognitivos, como a capacidade perceptiva "de trabalhar com imagens mentais, com abstrações, generalizações, discriminações e classificações de figuras geométricas, entre outros" (NASCIMENTO et al, 2014, p. 10). Assim, a apropriação dos referidos conhecimentos é necessária para que a criança construa o direito de ler e de interpretar o espaço humano e social em que vive.

\section{Quadro 10 - Agrupador 11 (início e fim/2014)}

\begin{tabular}{|c|c|c|c|c|c|c|c|}
\hline $\begin{array}{l}\text { Reconhece } \\
\text { representações de } \\
\text { figuras geométricas } \\
\text { espaciais (pirâmide, } \\
\text { paralelepípedo, cubo) e } \\
\text { suas planificações. }\end{array}$ & Sim & $\%$ & Parc. & $\%$ & Não & $\%$ & Total \\
\hline Início & 55230 & 43,00 & 34890 & 27,10 & 38458 & 29,90 & 128578 \\
\hline Fim & 79288 & 70,60 & 21538 & 19,20 & 11422 & 10,20 & 112248 \\
\hline
\end{tabular}

Fonte: Idem Quadro 1.

A construção do conceito de percepção geométrica possibilita à criança reconhecer figuras geométricas planas e espaciais, bem como classificá-las de acordo com suas características (atributos). Um expressivo número de crianças no início do ano de 2014 
reconheciam parcialmente representações de figuras geométricas espaciais (pirâmide, paralelepípedo, cubo) e suas planificações ou não reconheciam. De acordo com os dados do Quadro 10, aproximadamente 73.348 crianças não tinham este conhecimento construído. Contudo, diante da importância da alfabetização, algumas dificuldades relacionadas ao seu ensino precisam ser superadas, como:

\begin{abstract}
trabalhá-la somente ao final do ano, como um campo desconectado de outros conteúdos como os de Números, Grandezas e Medidas e Estatística. Além disso, é necessário superar a ideia de que a Geometria se resume às figuras geométricas, trabalhando também com atividades de Movimentação e Localização de pessoas e objetos no espaço (NASCIMENTO et al, 2014, p. 11/12).
\end{abstract}

A formação continuada ofertada pelo Pnaic reforçou as recomendações. Geometria no ciclo da alfabetização não pode se resumir à memorização de algumas figuras planas e espaciais. No entanto, o vício pedagógico de trabalhá-la descontextualizada e desarticulada das demais disciplinas, apenas no final do ano letivo quando sobrar tempo, ainda não foi desconstruído nas salas de alfabetização de Mato Grosso. A orientação é que a formação continuada interdisciplinar aprofunde as discussões teóricas e práticas. A geometria precisa ser explorada concomitante às demais disciplinas, principalmente a geografia, que também alfabetiza a criança, ajudando-a a ler os espaços humanos, políticos, econômicos e sociais.

\title{
Quadro 11 - Agrupador 12 (início e fim/2014)
}

\begin{tabular}{l|c|c|c|c|c|c|c}
\hline $\begin{array}{l}\text { Utiliza corretamente } \\
\text { as ideias relacionadas } \\
\text { de direita de, esquerda } \\
\text { de, acima de, abaixo de, } \\
\text { dentro de, fora de. }\end{array}$ & Sim & $\%$ & Parc. & $\%$ & Não & $\%$ & Total \\
\hline Início & 85385 & 66,40 & 28582 & 22,20 & 14611 & 11,40 & 128578 \\
\hline Fim & 95942 & 85,50 & 12314 & 11,00 & 3992 & 3,60 & 112248 \\
\hline
\end{tabular}

Fonte: Idem Quadro 1.

Desenvolver noções de lateralidade é outro direito assegurado a toda criança no ciclo da alfabetização. Ela precisa construir ideias relacionadas à direita de, e à esquerda de, para localizar-se e movimentar-se no espaço em que vive, como também para estabelecer relações e ler os demais espaços geográficos. Complementam esses conhecimentos a apropriação de noções topológicas, como dentro e fora, e de vizinhança. Geralmente, a indicação é que essas noções sejam construídas a partir de pontos de referências estabelecidos. A própria criança, outras pessoas e objetos podem ser utilizados neste trabalho (NASCIMENTO et al, 2014). 
No início de 2014, aproximadamente 43.193 crianças matriculadas nas escolas públicas de Mato Grosso tinham estes conhecimentos parcialmente ou não construídos. No final do ano, os dados inseridos no Simec/SisPacto indicaram um avanço superior a 50\% em relação a este número.

Quadro 12 - Agrupador 13 (início e fim/2014)

\begin{tabular}{l|c|c|c|c|c|c|c}
\hline $\begin{array}{l}\text { Compara e ordena } \\
\text { comprimentos. }\end{array}$ & Sim & $\%$ & Parc. & $\%$ & Não & $\%$ & Total \\
\hline Início & 62775 & 48,80 & 34255 & 26,60 & 31545 & 24,50 & 128575 \\
\hline Fim & 86679 & 77,20 & 18409 & 16,40 & 7155 & 6,40 & 112243 \\
\hline
\end{tabular}

Fonte: Idem Quadro 1.

Comparar e ordenar comprimentos é uma habilidade que as crianças precisam construir para ter noção de grandezas e medidas. Os dados mostram que era expressivo o número de crianças com estes conhecimentos parcialmente ou não construídos no início de 2014, aproximadamente 65.800 crianças. Vianna (2014) considera possível que muitos estudantes concluam o seu processo de escolarização básica sem ter construído noções de aspectos importantes das medidas utilizadas no dia a dia. Segundo o autor, essa realidade se deve ao fato de que geralmente as escolas não propiciam aos estudantes estudos articulados a situações práticas de medidas. Ele adverte que "a falta de trabalho com as Grandezas e Medidas pode levar a resultados desastrosos para os alunos em séries mais avançadas" (p. 32).

\section{Quadro 13 - Agrupador 14 (início e fim/2014)}

\begin{tabular}{l|c|c|c|c|c|c|c|}
\hline $\begin{array}{l}\text { Identifica cédulas e } \\
\text { moedas realizando } \\
\text { composições, } \\
\text { decomposições e efetua } \\
\text { troco. }\end{array}$ & Sim & $\%$ & Parc. & $\%$ & Não & $\%$ & Total \\
\hline Início & 52985 & 41,20 & 40242 & 31,30 & 35338 & 27,50 & 128565 \\
\hline Fim & 77699 & 69,20 & 24595 & 21,90 & 9949 & 8,90 & 112243 \\
\hline
\end{tabular}

Fonte: Idem Quadro 1.

Mais de 50\% das crianças matriculadas no ciclo da alfabetização em Mato Grosso, de acordo com os dados inseridos no Simec/SisPacto, tinham parcialmente ou não construído os conhecimentos relativos a identificação de cédulas e moedas e a realização de composições e decomposições deste sistema de medidas, que permite efetuar pagamentos de valores e trocos, no início de 2014 . No final deste ano, mais de $30 \%$ do percentual 
de crianças continuaram com esse conhecimento parcialmente ou não construído. Todavia, reconhecer as cédulas e moedas no Sistema Monetário Brasileiro é um conhecimento que permite compreendê-lo e realizar trocas. A compreensão deste sistema permite às crianças "desenvolver um senso monetário, fazendo com que construam as noções (abstratas e subjetivas) de 'barato' e 'caro'"' (ROLKOUSKI, 2014a, p. 48). O autor destaca a importância de o professor trabalhar o processo histórico que originou a criação das unidades monetárias, como também, trabalhar práticas que possibilitem às crianças compreender esta necessidade e construir a ideia de consumo responsável. Como vemos, esse é mais um importante conhecimento que precisa ser explorado no ciclo da alfabetização para que a criança tenha o direito de aplicá-lo em suas práticas sociais.

\section{Quadro 14 - Agrupador 16 (início e fim/2014)}

\begin{tabular}{l|c|c|c|c|c|c|c}
\hline $\begin{array}{l}\text { Realiza medições } \\
\text { e comparações de } \\
\text { massa, comprimento e } \\
\text { capacidade com unidades } \\
\text { não padronizadas }\end{array}$ & Sim & $\%$ & Parc. & $\%$ & Não & $\%$ & Total \\
\hline Início & 42341 & 32,90 & 36849 & 28,70 & 49375 & 38,40 & 128565 \\
\hline Fim & 74920 & 66,70 & 25210 & 22,50 & 12113 & 10,80 & 112243 \\
\hline
\end{tabular}

Fonte: Idem Quadro 1.

Ser capaz de realizar medições e comparações de massa, comprimento e capacidade com unidades não padronizadas é fundamental para que as crianças construam conceitos que expressem a necessidade de utilizar medidas padronizadas em nossas práticas sociais cotidianas. Segundo Munhoz et al (2014), sua apropriação contribui para o exercício da cidadania. Os dados informam que 86.224 crianças estavam com estes conhecimentos parcialmente ou não construídos no início do ano de 2014. Porém, o avanço também foi superior a 50\%, número que corresponde aos demais direitos relacionados às medidas de massa, de capacidade, de comprimento e de tempo.

\section{Considerações finais}

Os agrupadores analisados neste texto representam parcialmente os direitos da aprendizagem matemática no ciclo da alfabetização. O Pnaic compartilha o direito de aprender, "como um direito humano objetivo" (TELES, 2014, p. 05). Este direito é essencial para a sobrevivência humana, nele estão as necessidades humanas "de ordem: material, espiritual e psicológica, sendo o ponto de partida o sentimento de solidariedade no relacionamento entre as pessoas" (Idem, p. 39). 
Na contemporaneidade, estas necessidades extrapolam a alimentação, o abrigo e outros bens e serviços obrigatórios. As pessoas têm o direito de ter uma formação que lhes permita participar ativamente da vida social, ou seja, que lhes dê condições de ser cidadã e de exercer a cidadania. Os direitos de aprendizagem desdobrados em "agrupadores" no Simec/SisPacto foram elaborados em atenção a estas necessidades. A formação ofertada pelo Pnaic insere-se à discussão de que em uma sociedade que tem como princípios uma educação que promova a justiça social, "a defesa e a promoção dos direitos humanos requerem a consciência clara sobre o papel da educação". Porém, é preciso lembrar que "o processo educacional, em si, contribui tanto para conservar, quanto para mudar valores, crenças, mentalidades, costumes e práticas" (TELES, 2014).

Para que a educação cumpra com a sua função social, ao final do $3^{\circ}$ ano de escolarização, todas as crianças precisam estar plenamente alfabetizadas: dominar a Língua, saber interpretar um texto simples e dominar os conhecimentos matemáticos elementares, para ter condições de agir de forma crítica socialmente e prosseguir exitosamente nos estudos (BRASIL, 2014).

Os percentuais apresentados correspondem a todas as crianças matriculadas no ciclo da alfabetização, e boa parte destes números podem representar as crianças matriculadas no $1^{\underline{0}}$ e no $2^{\underline{o}}$ anos deste ciclo. No entanto, de certa forma, eles exprimem o processo evolutivo dos alfabetizandos, bem como informam a correlação entre um e outro direito de aprendizagem. A evolução reafirma que a apropriação do conhecimento é um processo, e como todo processo demanda continuidade, a exemplo da política analisada nesta investigação. Os indicadores indicam avanços em decorrência das ações realizadas pelo Pnaic em 2014. No entanto, mudanças mais significativas estão condicionadas à continuidade dessa política.

Recebido em 20/06/2016 e aprovado em 22/08/2016

\section{Notas}

1 Informações disponíveis em: http://portal.mec.gov.br/index.php?option=com_content\&id=143:simec. Acesso em maio de 2015.

2 Informações disponíveis em: http://pacto.mec.gov.br/31-outros-destaques/79-entenda-o-sispacto. Acesso em: maio de 2015

3 "Algoritmos são procedimentos de cálculo que envolvem técnicas com passos ou sequências determinadas que conduzem a um resultado" (GUERIOS et al, 2014a, p. 07). 


\section{Referências}

BRASIL. Ministério da Educação. Secretaria de Educação Básica. Diretoria de Apoio a Gestão Educacional. Pacto Nacional Pela Alfabetização na Idade Certa. Avaliação no ciclo da alfabetização: reflexões e sugestões. Brasília: 2012.

BRASIL. Secretaria de Educação Básica. Diretoria de Apoio à Gestão Educacional. Pacto Nacional pela Alfabetização na Idade Certa: Quantificação, registros e agrupamentos. Caderno 02. Brasília: MEC, SEB, 2014.

GUERIOS, Ettiene Cordeiro et al. Situações aditivas e multiplicativas no ciclo da alfabetização. In.: BRASIL, Secretaria de Educação Básica. Diretoria de Apoio à Gestão Educacional. Pacto Nacional pela Alfabetização na Idade Certa: Operações na resolução de problemas. Caderno 04. Brasília: MEC, SEB, 2014.

. et al. Ao chegar à escola... In.: BRASIL, Secretaria de Educação Básica. Diretoria de Apoio à

Gestão Educacional. Pacto Nacional pela Alfabetização na Idade Certa: Operações na resolução de problemas. Caderno 04. Brasília: MEC, SEB, 2014a.

LOPES, Anemari Roesler Luersen Vieira et al. Número: de qualidades a quantidades. In.: BRASIL, Secretaria de Educação Básica. Diretoria de Apoio à Gestão Educacional. Pacto Nacional pela Alfabetização na Idade Certa: Quantificação, registros e agrupamentos. Caderno 02. Brasília: MEC, SEB, 2014.

MARCONI, M. A. \& LAKATOS, E. M. Técnicas de Pesquisa: planejamento e execução de pesquisas, amostragens e técnicas de pesquisas, elaboração, análise e interpretação de dados. 5. ed. São Paulo: Atlas, 2002.

MOCROSKY, Luciane Ferreira et al. A contagem e o universo infantil. In.: BRASIL, Secretaria de Educação Básica. Diretoria de Apoio à Gestão Educacional. Pacto Nacional pela Alfabetização na Idade Certa: Quantificação, registros e agrupamentos. Caderno 02. Brasília: MEC, SEB, 2014.

MUNHOZ, Danilo Pereira et al. A importância de ensinar grandezas e medidas. In.: BRASIL, Secretaria de Educação Básica. Diretoria de Apoio à Gestão Educacional. Pacto Nacional pela Alfabetização na Idade Certa: Grandezas e Medidas. Caderno 06. Brasília: MEC, SEB, 2014.

NASCIMENTO, Andréia Aparecida da Silva Brito et al. A Geometria e o Ciclo de Alfabetização. In.: BRASIL, Secretaria de Educação Básica. Diretoria de Apoio à Gestão Educacional. Pacto Nacional pela Alfabetização na Idade Certa: Geometria. Caderno 05. Brasília: MEC, SEB, 2014.

ROLKOUSKI, Emerson. As operações, as práticas sociais e a calculadora. In.: BRASIL, Secretaria de Educação Básica. Diretoria de Apoio à Gestão Educacional. Pacto Nacional pela Alfabetização na Idade Certa: Operações na resolução de problemas. Caderno 04. Brasília: MEC, SEB, 2014.

. Valor Monetário. In.: BRASIL, Secretaria de Educação Básica. Diretoria de Apoio à Gestão Educacional. Pacto Nacional pela Alfabetização na Idade Certa: Grandezas e Medidas. Caderno 06. Brasília: MEC, SEB, 2014a.

TELES, Rosinalda Aurora de Melo. Direitos e objetivos de aprendizagem e desenvolvimento: a Matemática como instrumento de formação e promoção humana. In.: BRASIL, Secretaria de Educação Básica. Diretoria de Apoio à Gestão Educacional. Pacto Nacional pela Alfabetização na Idade Certa: Apresentação, Alfabetização Matemática. Brasília: MEC, SEB, 2014.

VIANNA, Carlos Roberto. Afinal, o que é medir? . In.: BRASIL, Secretaria de Educação Básica. Diretoria de Apoio à Gestão Educacional. Pacto Nacional pela Alfabetização na Idade Certa: Grandezas e Medidas. Caderno 06. Brasília: MEC, SEB, 2014. 